\title{
Experimental investigation of the susceptibility of Italian Culex pipiens mosquitoes to Zika virus infection
}

D Boccolini ${ }^{12}$, L Toma $^{12}$, M Di Luca ${ }^{1}$, F Severini ${ }^{1}$, R Romi $^{1}$, ME Remoli $^{1}$, M Sabbatucci $^{13}$, G Venturi $^{1}$, G Rezza $^{1}$, C Fortuna $^{1}$

1. Department of Infectious Diseases, Istituto Superiore di Sanità, Rome, Italy

2. These authors contributed equally to this manuscript

3. European Programme for Public Health Microbiology Training (EUPHEM), European Centre for Disease Prevention and Control (ECDC), Stockholm, Sweden

Correspondence: Claudia Fortuna (claudia.fortuna@iss.it)

Citation style for this article:

Boccolini D, Toma L, Di Luca M, Severini F, Romi R, Remoli ME, Sabbatucci M, Venturi G, Rezza G, Fortuna C. Experimental investigation of the susceptibility of Italian Culex pipiens mosquitoes to Zika virus infection. Euro Surveill. 2016;21(35):pii=30328. DOI: http://dx.doi.org/10.2807/1560-7917.ES.2016.21.35.30328

Article submitted on 11 August 2016 / accepted on 1 September 2016 / published on 1 September 2016

We investigated the susceptibility of an Italian population of Culex pipiens mosquitoes to Zika virus (ZIKV) infection, tested in parallel with Aedes aegypti, as a positive control. We analysed mosquitoes at $0,3,7$, 10, 14, 20 and 24 days after an infectious blood meal. Viral RNA was detected in the body of $C x$. pipiens up to three days post-infection, but not at later time points. Our results indicate that $C x$. pipiens is not susceptible to ZIKV infection.

Since its emergence in South and Central America in 2014, Zika virus (ZIKV) has spread rapidly, resulting in an unprecedentedly large number of infections [1-4]. It is well accepted that Aedes species are the main vectors of ZIKV [5-7]. However, in order to assess the risk of spread of this infection to new areas, it is pivotal to investigate the possibility that mosquito species belonging to other genera could contribute to sustaining virus transmission. Culex pipiens is widespread in Mediterranean countries [8], and little is known at present about its potential role as ZIKV vector. We report here our findings on experimental infection of an Italian population of Culex pipiens mosquitoes with ZIKV, using Ae. aegypti mosquitoes as a positive control. Using quantitative reverse transcription PCR (qRT$P(R)$ to detect viral RNA, our findings indicate that $C X$. pipiens is not susceptible to ZIKV infection.

\section{Experimental infection of mosquitoes}

Experimental infection of the mosquitoes, starting in April 2016, was performed using the ZIKV H/ $\mathrm{PF} / 2013$ strain, of the Asian genotype (kindly provided by $\mathrm{Dr}$ Isabelle Leparc-Goffart of the French National Reference Centre for Arboviruses in Marseille) isolated from a patient returning from French Polynesia in 2013 [9]. We exposed 10 day-old female mosquitoes from an Italian Cx. pipiens population (collected in Rome, Latium Region, in the summer of 2015) and from a long-established colony of Ae. aegypti (collected in Reynosa, Mexico, in 1998) to an infectious blood meal for one hour, through a membrane feeding apparatus.
The virus was diluted in rabbit blood (final virus concentration: $6.46 \log _{10}$ plaque-forming units (PFU)/mL) and maintained at $37^{\circ} \mathrm{C}$ by a warm-water circulation system. After the blood meal, fully engorged females were transferred to other cages and maintained on a $10 \%$ sucrose solution in a climatic chamber $\left(26 \pm 1^{\circ} \mathrm{C}\right.$; $70 \%$ relative humidity; 14 hour light:10 hour dark cycle) for 24 days. A total of 8-10 mosquitoes from both species were processed individually at $0,3,7,10,14,20$ and 24 dpi.

To evaluate viral infection, dissemination and transmission, body (head, thorax and abdomen), legs plus wings, and saliva were analysed, as previously described [10]. The viral titre was evaluated by qRTPCR. Specific primers ZIKV 1086 and ZIKV 1162C were used, with 5-FAM as the reporter dye for the probe (ZIKV 1107-FAM) [11]. Crossing point values were compared with a standard curve obtained from 10-fold serial dilutions of virus stock of known concentration [7].

Mosquito bodies were analysed in order to evaluate the infection rate, calculated as the number of ZIKVpositive mosquito bodies out of the total number of fed females. Legs plus wings were tested to assess the dissemination rate, calculated as the number of the specimens with ZIKV-positive legs plus wings among the tested mosquitoes. The saliva of the potentially infected females was processed to assess the transmission rate, defined as the number of mosquitoes with ZIKV-positive saliva among the number of tested mosquitoes $[7,10]$.

\section{Vector competence analysis}

All the $C x$. pipiens $(n=10)$ and Ae. aegypti $(n=8)$ bodies analysed at day o (i.e. immediately after the infectious blood meal) showed positive results, with mean viral titres of 4.23 (standard deviation (SD): 0.07) $\log _{10}$ PFU/ $\mathrm{mL}$ and 3.7 (SD: 0.18) $\log _{10} \mathrm{PFU} / \mathrm{mL}$, respectively, confirming the ingestion of viral particles. 
At $3 \mathrm{dpi}$, only one of $10 C x$. pipiens mosquitoes analysed was infected. In the $C x$. pipiens body, viral RNA was detected at a low concentration ( $0.17 \log _{10}$ PFU/ $\mathrm{mL}$ ), whereas no viral RNA was detected at the later collection times. Viral RNA was never detected in legs plus wings and in the saliva of the $C x$. pipiens (Table).

These findings differed greatly with those obtained with Ae. aegypti. As expected, in Ae. aegypti, the viral titres detected in the mosquito bodies increased gradually, reaching a mean value of 5.12 (SD: 0.06$) \log _{10}$ PFU/ $\mathrm{mL}$ at $14 \mathrm{dpi}$, as well as in legs plus wings and in the saliva, showing an extrinsic incubation period similar to that previously described [7]. The infection rate at 7 dpi was $6 / 12$ as was found for the dissemination rate. At the same collection time, ZIKV was detected also in the saliva with a transmission rate of $2 / 12$ and a mean viral titre of 1.80 (SD: 0.14) $\log _{10} \mathrm{PFU} / \mathrm{mL}$. In the later collection points, ZIKV was detected in body, legs plus wings and saliva confirming the expected vector competence of this mosquito species (Table).

\section{Discussion}

In countries where ZIKV has recently spread, Ae. aegypti and Ae. albopictus have been recognised as the most efficient vectors [5-7]. There is limited evidence that ZIKV can infect other mosquito species naturally: the presence of the virus has been reported in species of the Culex genus in Senegal and in Brazil $[12,13]$. Following our study on ZIKV competence of an Italian Ae. albopictus population [7], we investigated the susceptibility of an Italian population of the widespread indigenous species $C X$. pipiens [8] to ZIKV infection under laboratory conditions. Increasing concern about the spread of ZIKV and its epidemic potential [1-4] makes it particularly important to fill gaps in knowledge about the role that mosquitoes other than $A e$. albopictus and Ae. aegypti may have in the circulation and transmission of this virus in the Mediterranean area.

We focused our attention on $C x$. pipiens mosquitoes as a potential ZIKV vector, since these mosquitoes are ubiquitous in temperate and tropical areas, where they are involved in the transmission of a range of human and zoonotic pathogens, such as West Nile virus, St Louis encephalitis virus, Rift Valley Fever virus, filarial worms and avian malaria $[14,15]$. The important vector role of $C x$. pipiens arises from its opportunistic host feeding behaviour and on the high abundance it can reach in rural as well as in urban settings $[14,15]$.

Our results show that the Italian $C x$. pipiens population tested was not susceptible to ZIKV; the short persistence of the virus in the mosquito's body does not allow viral replication and, consequently, viral dissemination in the salivary glands. Conversely, our results showed Ae. aegypti to be competent for ZIKV transmission, as previously reported [7].

\section{TABLE}

Competence for Zika virus (infection, dissemination and transmission rates) ${ }^{\mathrm{a}}$ and Zika virus titres in body, legs plus wings and saliva of Culex pipiens and Aedes aegypti colonies fed orally ${ }^{\mathrm{b}, \mathrm{c}}$

\begin{tabular}{|c|c|c|c|c|c|c|c|c|c|c|c|c|}
\hline \multirow[b]{2}{*}{ 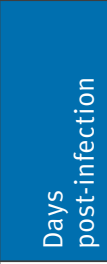 } & \multicolumn{6}{|c|}{ Cx. pipiens } & \multicolumn{6}{|c|}{ Ae. aegypti } \\
\hline & 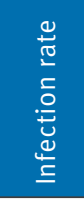 & 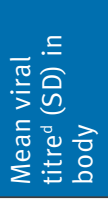 & 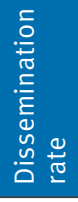 & 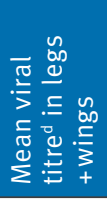 & 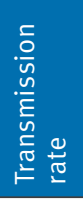 & 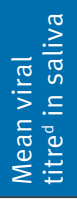 & 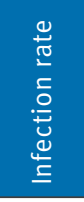 & 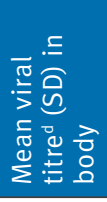 & 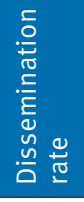 & 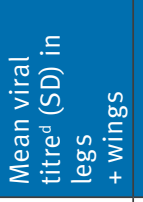 & 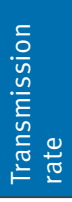 & 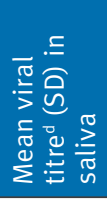 \\
\hline $0^{e}$ & $10 / 10$ & $\begin{array}{c}4.23 \\
(0.07) \\
\end{array}$ & $0 / 10$ & 0 & $0 / 10$ & 0 & $8 / 8$ & $\begin{array}{c}3.73 \\
(0.18)\end{array}$ & $0 / 8$ & 0 & $0 / 8$ & 0 \\
\hline 3 & $1 / 10$ & 0.17 & $0 / 10$ & 0 & $0 / 10$ & 0 & ND & ND & ND & ND & ND & ND \\
\hline 7 & $0 / 10$ & 0 & $0 / 10$ & 0 & $0 / 10$ & 0 & $6 / 12$ & $\begin{array}{c}3.76 \\
(1.25) \\
\end{array}$ & $6 / 12$ & $\begin{array}{c}2.57 \\
(0.32) \\
\end{array}$ & $2 / 12$ & $\begin{array}{c}1.80 \\
(0.14) \\
\end{array}$ \\
\hline 10 & $0 / 10$ & 0 & $0 / 10$ & 0 & $0 / 10$ & 0 & ND & ND & ND & ND & ND & ND \\
\hline 14 & $0 / 10$ & 0 & $0 / 10$ & 0 & $0 / 10$ & 0 & $4 / 8$ & $\begin{array}{c}5.12 \\
(0.06)\end{array}$ & $4 / 8$ & $\begin{array}{c}3.11 \\
(0.36)\end{array}$ & $3 / 8$ & $\begin{array}{c}2.05 \\
(0.97)\end{array}$ \\
\hline 20 & $0 / 10$ & 0 & $0 / 10$ & 0 & $0 / 10$ & 0 & $4 / 10$ & $\begin{array}{c}4.60 \\
(0.21) \\
\end{array}$ & $3 / 10$ & $\begin{array}{c}3.08 \\
(0.28) \\
\end{array}$ & $3 / 10$ & $\begin{array}{c}2.10 \\
(0.39) \\
\end{array}$ \\
\hline 24 & $0 / 10$ & 0 & $0 / 10$ & 0 & $0 / 10$ & 0 & ND & ND & ND & ND & ND & ND \\
\hline
\end{tabular}

ND: not detected; SD: standard deviation.

a Infection rate: number of virus-positive bodies/number of tested females; dissemination rate: number of virus-positive legs plus wings/ number of tested females; transmission rate: number of virus-positive saliva samples/number of tested females.

b The mosquitoes were kept at $26^{\circ} \mathrm{C}$ and collected at various days post-infection.

c The viral titre was evaluated by quantitative reverse transcription PCR (qRT-PCR). Crossing point values were compared with a standard curve obtained from 10 -fold serial dilutions of virus stock of known concentration [7].

d Expressed as log10 plaque-forming units $/ \mathrm{mL}$.

e Immediately after the infectious blood meal. 
Similar results were reported in a recent study on ZIKV susceptibility of a $C X$. pipiens population from the United States [16], showing that this species is not a competent vector for ZIKV. However, in Brazil, current studies have reported ZIKV detection in the salivary glands of $C X$. quinquefasciatus that were artificially fed with ZIKV-infected blood, and tested 7 and 15 days post-feeding $[13,17]$.

We did not carry out viral titration by plaque formation as we observed in a previous study a high correlation between titration by this method and viral RNA detection [10]: this may constitute a limitation of this study.

In conclusion, the findings of the studies conducted on Italian and United States populations of $C x$. pipiens mosquitoes have important public health implications, and help to optimise the vector control activities in Italy, should autochthonous ZIKV transmission occur. $C x$. pipiens mosquito populations in Italy are unlikely to be competent vectors for ZIKV. Thus, to date, Ae. albopictus is the only mosquito established in Italy for which vector competence for ZIKV has been demonstrated [7]. However, even if a low epidemic potential risk of ZIKV in Italy was estimated [18], it should be considered that arboviruses have the potential to rapidly change their vector-host associations [19]. Therefore further vector competence studies should be undertaken in order to plan evidence-based interventions.

\section{Acknowledgements}

We would like to thank Andrea Martinelli and Antonio Di Virgilio for their technical support to the infection experiments.

\section{Conflict of interest}

None declared.

\section{Authors' contributions}

BD, TL, DLM, SF, RME, SM, VG and FC performed the experiments; BD, TL, DLM, SF, VG and FC analysed the data; BD, TL, DLM, SF, VG, RR, VG, RG and FC wrote the manuscript.

\section{References}

1. Hennessey M, Fischer M, Staples JE. Zika virus spreads to new areas - region of the Americas, May 2015-January 2016. MMWR Morb Mortal Wkly Rep. 2016;65(3):55-8. DOI: 10.15585/ mmwr.mm6503e1 PMID: 26820163

2. United States Centers for Disease Control and Prevention (CDC). Countries and Territories with Active Local Zika Virus Transmission. Atlanta, GA: CDC. [Accessed 31 Aug 2016]. Available from: http://www.cdc.gov/zika/geo/active-countries. html

3. Campos GS, Bandeira AC, Sardi SI. Zika virus outbreak, Bahia, Brazil.Emerg Infect Dis. 2015;21(10):1885-6. DOI: 10.3201/ eid2110.150847 PMID: 26401719

4. Zika virus outbreaks in the Americas. Wkly Epidemiol Rec. 2015;90(45):609-10.PMID: 26552108

5. Kraemer MU, Sinka ME, Duda KA, Mylne AQ, Sheare FM, Barker CM, et al. The global distribution of the arbovirus vectors Aedes aegypti and Ae. albopictus. elife. 2015;4:e08347. DOI: 10.7554/eLife.08347 PMID: 26126267
6. Chouin-Carneiro T, Vega-Rua A, Vazeille M, Yebakima A, Girod R, Goindin D. Differential susceptibilities of Aedes aegypti and Aedes albopictus from the Americas to Zika virus. PLoS Negl Trop Dis. 2016;10(3):eoo04543. eCollection 2016. DOI: DOI: 10.1371/journal.pntd.0004543

7. Di Luca M, Severini F, Toma L, Boccolini D, Romi R, Remoli ME, et al. Experimental studies of susceptibility of Italian Aedes albopictus to Zika virus. Euro Surveill. 2016;21(18):30223. DOI: 10.2807/1560-7917.ES.2016.21.18.30223 PMID: 27171034

8. Di Luca M, Toma L, Boccolini D, Severini F, La Rosa G, Minelli $\mathrm{G}$, et al. Ecological Distribution and $\mathrm{CQ}_{11}$ Genetic Structure of Culex pipiens Complex (Diptera: Culicidae) in Italy. PLoS One. 2016;11(1):e0146476. DOI: DOI: 10.1371/journal.pone.0146476 . e Collection 2016.

9. Baronti C, Piorkowski G, Charrel RN, Boubis L, Leparc-Goffart I, de Lamballerie X. Complete coding sequence of zika virus from a French polynesia outbreak in 2013.Genome Announc. 2014;2(3):e00500-14. DOI: 10.1128/genomeA.00500-14 PMID: 24903869

10. Fortuna C, Remoli ME, Di Luca M, Severini F, Toma L, Benedetti $E$, et al. Experimental studies on comparison of the vector competence of four Italian Culex pipiens populations for West Nile virus. Parasit Vectors. 2015;8(1):463. DOI: 10.1186/s13071015-1067-z PMID: 26383834

11. Lanciotti RS, Kosoy OL, Laven JJ, Velez JO, Lambert AJ, Johnson AJ, et al. Genetic and serologic properties of Zika virus associated with an epidemic, Yap State, Micronesia, 2007. Emerg Infect Dis. 2008;14(8):1232-9. DOI: 10.3201/ eid1408.080287 PMID: 18680646

12. Diallo D, Sall AA, Diagne CT, Faye O, Faye O, Ba Y, et al. Zika virus emergence in mosquitoes in southeastern Senegal. 2011. PLoS One. 2014;9(10):e109442. doi: DOI: 10.1371/journal. pone.0109442. eCollection 2014.

13. Fundação Oswaldo Cruz (Fiocruz). Fiocruz identifica Culex no Recife com potencial para transmitir o vírus zika). [Fiocruz identifies in Recife Culex with the potential to transmit Zika virus].21 July 2016. Rio de Janeiro: Fiocruz; 2016. Brazilian. Available from: https://agencia.fiocruz.br/fiocruz-identificaculex-no-recife-com-potencial-para-transmitir-o-virus-zika

14. Turell MJ. Members of the Culex pipiens complex as vectors of viruses.J Am Mosq Control Assoc. 2012;28(4) Suppl;123-6. DOI: 10.2987/8756-971X-28.4.123 PMID: 23401952

15. Farajollahi A, Fonseca DM, Kramer LD, Marm Kilpatrick A. "Bird biting" mosquitoes and human disease: a review of the role of Culex pipiens complex mosquitoes in epidemiology. Infect Genet Evol. 2011;11(7):1577-85. DOI: 10.1016/j. meegid.2011.08.013 PMID: 21875691

16. Aliota MT, Peinado SA, Osorio JE, Bartholomay LC. Culex pipiens and Aedes triseriatus Mosquito Susceptibility to Zika virus.Emerg Infect Dis. 2016;22(10). DOI: 10.3201/ eid2210.161082 PMID: 27434194

17. Franca RFO, Neves MHL, Ayres CFJ, Melo-Neto OP, Brandão Filho SP. First International Workshop on Zika Virus Held by Oswaldo Cruz Foundation FIOCRUZ in Northeast Brazil March 2016 - A Meeting Report. PLoS Negl Trop Dis. 2016;10(6):eoo04760. doi: DOI: 10.1371/journal.pntd.0004760 . eCollection 2016.

18. Guzzetta G, Poletti P, Montarsi F, Baldacchino F, Capelli $\mathrm{G}$, Rizzoli A, et al. Assessing the potential risk of Zika virus epidemics in temperate areas with established Aedes albopictus populations. Euro Surveill. 2016;21(15):30199. DOI: 10.2807/1560-7917.ES.2016.21.15.30199 PMID: 27104366

19. Coffey LL, Failloux AB, Weaver SC. Chikungunya virus-vector interactions.Viruses. 2014;6(11):4628-63. DOI: 10.3390/ v6114628 PMID: 25421891

\section{License and copyright}

This is an open-access article distributed under the terms of the Creative Commons Attribution (CC BY 4.0) Licence. You may share and adapt the material, but must give appropriate credit to the source, provide a link to the licence, and indicate if changes were made.

This article is copyright of the authors, 2016. 